\title{
Avicena e a filosofia oriental: história de uma controvérsia
}

\author{
Avicenna and the oriental philosophy: \\ history of a controversy
}

\section{Rosalie Helena de Souza Pereira}

Mestre em Filosofia (FFLCH-USP), Doutora em Filosofia (IFCH-UNICAMP), pesquisadora em estágio de Pós-Doutorado no Programa de Filosofia da Pontifícia Universidade Católica de São Paulo (PUC-SP), São Paulo, SP - Brasil, e-mail: rosaliepereira@uol.com.br

\section{Resumo}

Uma obra incompleta de Avicena (Ibn Sīnā), a Filosofia Oriental, concentrou a atenção de muitos especialistas para determinar seu título e conteúdo. Alguns julgaram tratar-se de uma obra de conteúdo místico e aceitaram o título de Filosofia Iluminativa, o que foi refutado unanimemente com a publicação, em 1925, do artigo de C. A. Nallino e, mais recentemente, em 1988, com o trabalho de D. Gutas. A mística na obra de Avicena, porém, continuou a ser estudada com base em seus outros textos. Na década de 1950, Henry Corbin reviveu a polêmica em torno do título da controvertida obra de Avicena, desenvolvendo a hermenêutica de uma filosofia oriental-iluminativa e, nesta linha, a interpretação de três opúsculos de Avicena. Foi contestado por 
Amélie-Marie Goichon em seu estudo sobre a Narrativa de Hayy ibn Yaqzān, um dos três opúsculos estudados por Corbin. Apresenta-se aqui a história da polêmica acerca do título da obra parcialmente perdida de Avicena e, relacionada a esta questão, a concepção de Oriente e Ocidente nos estudos avicenianos. Ao interpretarem Hayy ibn Yaqzān, Corbin e Goichon seguem métodos distintos: Goichon segue o paradigma do aristotelismo e Corbin elabora uma hermenêutica fenomenológica para explicar a simbologia da viagem da alma em direção ao conhecimento.

Palavras-chave: Avicena. Filosofia Oriental. Filosofia Iluminativa. Filosofia Oriental-Iluminativa. Misticismo.

\section{Abstract}

Specialists concentrated their attention in order to determine the title and content of Avicenna's incomplete treatise Oriental Philosophy. Some thought of it as a work of mystical content and so accepted Illuminationist Philosophy as its title. With the publication in 1925 by C. A. Nallino's article, and more recently in 1988, by the work of D. Gutas, this was not unanimously accepted. The mysticism in Avicenna's work however continued to be studied in his other texts. In the 1950s Henry Corbin revived the polemic around the title of this controversial work of Avicenna and developed a Hermeneutic of an Oriental-Illuminationist Philosophy and in this line of thought also the interpretation of three of Avicenna's epistles. This was refuted by Amélie-Marie Goichon in her study of Hayy ibn Yaqzān, one of the three epistles studied by Corbin. I present here the history of the polemic around the title of this partially lost treatise of Avicenna, the Oriental Philosophy. Related to this matter is the East-West conception in the Avicennian studies. Corbin and Goichon follow distinct methods in their interpretation of Hayy ibn Yaqzān: Goichon follows the Aristotelian paradigm and Corbin elaborates a Hermeneutic based on Phenomenology in order to explain the symbology of the soul's journey towards knowledge.

Keywords: Avicenna. Oriental Philosophy. Illuminationist Philosophy. Oriental-Illuminationist Philosophy. Mysticism. 


\section{Introdução}

Foi recentemente publicado na revista Tiraz, n. 6, do Departamento de Línguas Orientais da FFLCH-USP, um artigo de Amélie-Marie Goichon, traduzido para o português, cujo título indica o propósito de sua tese: "O pretenso esoterismo de Avicena no Relato de Hayy ibn Yaqzān". Inicialmente uma comunicação no XXIV Congresso de Orientalistas que ocorreu em Munique, em 31 de agosto de 1957, o texto de Goichon foi publicado em Turim, no Giornale di Metafisica, n. 4, em 1959. A tradutora do artigo escreve em sua pequena introdução que

na visão da emérita orientalista, o pretenso esoterismo atribuído ao filósofo em alguns de seus escritos nada mais é do que o conjunto de imagens, alegorias e símbolos de uma intricada e sólida estrutura epistemológica e metafísica, a qual pode ser encontrada em seus escritos filosóficos, particularmente em Al-Shifā' (A Cura), restando a defesa da mística e do esoterismo àqueles que, deficientes em sua visão e em sua formação, negligenciaram o estudo da filosofia (DAMIEN, 2009, p. 110).

Ora, em nenhum momento do dito artigo Goichon faz menção, sequer alusão, a "deficientes em sua visão e em sua formação que negligenciaram o estudo da filosofia"! Estes jamais seriam qualificativos dados a estudiosos da obra de Avicena pela orientalista francesa, como confirmam suas próprias palavras no início de um de seus artigos: "Em avicenismo, não negamos a ninguém o direito de não ter a mesma opinião que a nossa" (GOICHON, 1952, p. 497). Esses "deficientes" aos quais se refere a tradutora compõem uma plêiade de arabistas do porte de Georges C. Anawati, Abdurrahmān Badaw̄̄, Henry Corbin, Louis Gardet, Louis Massignon, Salvador Gómez Nogales, Miguel Cruz Hernández, Miguel Asín Palácios, Jean Michot e outros, os quais jamais "negligenciaram o estudo da filosofia". E, não obstante o debate que travou com Henry Corbin sobre a questão do "esoterismo" de Avicena, Goichon jamais questionou a solidez filosófica desse pensador.

A questão do misticismo e/ou esoterismo de alguns textos de Avicena está inserida numa longa controvérsia entre vários especialistas sobre o conteúdo de uma "filosofia oriental" atribuída ao filósofo e médico persa. Perguntase, portanto, qual é o propósito de publicar um texto desvinculado do contexto 
em que ele foi concebido, acompanhado de julgamentos de valor extrínsecos e desprovidos de veracidade? ${ }^{1}$

O problema é complexo e não se reduz nem a "uma deficiência de visão e de formação", nem a "uma negligência do estudo da filosofia", como ficará claro no decorrer do presente artigo.

\section{O problema}

Há um conjunto de escritos atribuídos a Avicena que gerou três distintas linhas de interpretação adotadas pelos especialistas, cujo desacordo está em parte associado às divergências sobre o conteúdo da Filosofia Oriental do grande filósofo e médico persa. São elas:

a) o misticismo atribuído a um conjunto de textos avicenianos publicados no século XIX por Auguste F. Mehren (MEHREN, 1889-1889);

b) a filosofia oriental-iluminativa atribuída a alguns textos de Avicena por Henry Corbin (CORBIN, 1979);

c) a filosofia racional desses mesmos textos, defendida por AmélieMarie Goichon com base na doutrina aristotélica.

A questão do misticismo e/ou esoterismo de certas obras de Avicena está inserida num amplo debate que tem como fonte a sua Filosofia Oriental. De início, é preciso esclarecer o que é a Filosofia Oriental de Avicena, a origem do pomo de discórdia entre os especialistas. Filosofial Sabedoria Oriental (Al-Hikma al-Mashriqīya) é o título atribuído por estudiosos dos séculos XIX e XX a uma obra de Avicena da qual restam apenas o Prólogo, partes da Lógica e, de acordo com pesquisas recentes, partes

\footnotetext{
Apresentei, em linhas gerais, o histórico desse debate em minha dissertação de mestrado, defendida no Departamento de Filosofia da FFLCH-USP em 1998, depois publicada em livro: PEREIRA, R. H. S. Avicena: a viagem da alma. São Paulo: Editora Perspectiva, $2002^{1}, 2005^{2}$, que aqui retomo com modificações e acréscimos. Os autores que lidam com o tema do misticismo na obra de Avicena (Jean Michot, Salvador Gómez Nogales, Miguel Cruz Hernández, Sohleil M. Afnan, Seyyed Hossein Nasr, Shams C. Inati, e tantos outros) mereceriam destaque, mas, no âmbito de um artigo como este, não foi possível apresentar suas abordagens. Em razão de problemas técnicos, a transliteração dos termos árabes aqui adotada é a mais simples possível e não segue qualquer padrão estabelecido.
} 
da Física². Uma vez que Avicena menciona uma única vez os "orientais" (al-mashriqūyūn) neste Prólogo, faz menção aos "orientais" outras 46 vezes em outros tantos escritos, faz sete vezes referência a uma filosofia/sabedoria oriental (al-hikma al-mashriqīya) em sua obra Al-Shifä', além de mencionar outras expressões com o termo, como, por exemplo, os "princípios orientais", a "demonstração oriental", as "questões orientais" (GUTAS, 1988, p. 115-117), alguns autores se apressaram em atribuir a certos escritos da obra do filósofo persa um conteúdo esotérico ou místico com base em uma suposta "filosofia oriental" que Avicena teria elaborado para contrapor-se ao racionalismo peripatético. Nada mais incorreto, pois como bem demonstrou Shlomo Pines em seu artigo "La 'Philosophie Orientale' d'Avicenne et sa polémique contre les Bagdadiens", publicado em 1953, os "orientais" a que se refere Avicena são os cristãos nestorianos de Bagdá, cujo mestre Ibn Tayyib (m. 1043) é alvo do ódio e do desprezo da parte de Avicena, o qual até escreveu um tratado refutando um de seus textos (PINES, 1953, p. 16-17). A polêmica de Avicena com o grupo de Bagdá girava basicamente em torno da questão da sobrevivência da alma após a morte do corpo físico.

Nos fragmentos da Filosofia Oriental que sobreviveram, Avicena ainda menciona os "ocidentais" ao apresentar algumas correções à lógica: "Os ocidentais (al-magribīyunn) erram em considerar o modo na contradição das proposições necessárias e possíveis e em não considerá-lo no absoluto. Pois a acepção absoluta é também um modo" (AVICENA [IBN SĪNĀ], 1951, p. 137, n. 2).

Nesta passagem, Avicena parece referir-se aos filósofos herdeiros do peripatetismo, que viviam a oeste do Irã. Na argumentação sobre a lógica, como fica evidente, a referência aos "ocidentais" não indica nenhuma oposição a "orientais" de coloração mística.

$\mathrm{Na}$ esteira de Pines, Dimitri Gutas dedicou-se a desemaranhar o problema em seu Avicena and the Aristotelian Tradition, publicado em 1988. Para Gutas, porém, Pines, em sua argumentação, não esclareceu enfaticamente que Mashriq (Oriente) refere-se ao Khurāsān, região da Pérsia, a leste (Oriente) do atual Iraque (GUTAS, 1988, p. 127, n. 26).

2 Recentemente, foram encontrados quatro manuscritos contendo a Física, que, porém, nada contêm sobre a Lógica. Desse modo, é difícil estabelecer se pertencem ou não à Filosofia Oriental, ainda mais que toda a parte sobre a Física é copiada verbatim da Shifā'. Sobre essas descobertas, ver GUTAS, 2000. 
Gutas afirma que a escolha do nome "filosofia oriental" reflete a formação de Avicena na parte oriental do mundo islâmico (Mashriq), precisamente na tradição filosófica divulgada pela escola de filosofia aristotélica situada no Khurāsān (GUTAS, 1988, p. 127). Foi este o significado que os seguidores de Avicena na Espanha islâmica compreenderam e transmitiram para Averróis, o qual menciona, em seu Tahāfut al-Tahāfut, que Avicena chamou de "filosofia oriental" a doutrina divulgada pelos filósofos do Oriente (= Khurāsān) (AVERRÓIS, 1954, p. 254, v. I).

Os que defendem uma posição estritamente racional da filosofia de Avicena recorrem, paradoxalmente, a uma passagem do pensador persa Shihāb al-Din Suhrawardī (c. 1151-c. 1191). Posterior a Avicena, Suhraward̄̄ criticou a falta de uma doutrina "iluminativa" nas obras de Avicena. O Sheikh al-Ishrāq (Mestre da Iluminação), como era chamado, sublinhou sua estranheza por nada encontrar de especificamente "oriental" na filosofia de Avicena, principalmente na obra que ele conhecia com o título de Os Cadernos (CORBIN, 1979, p. 49-50), obra que posteriormente recebeu o título de Filosofia Oriental. No Prefácio do Relato do Exílio Ocidental (Qissat alGhurbat al-Gharbīya), Suhrawardī observa que, não obstante "as admiráveis frases espirituais e as profundas sugestões" contidas no escrito de Avicena, a Narrativa de Hayy ibn Yaqzān, nada lá encontrou a respeito do "segredo que consolida as etapas espirituais dos sūfis e daqueles que possuem a intuição visionária [...] exceto no final do livro", lá onde Avicena menciona que "os anacoretas espirituais emigram em direção a Ele" (SUHRAWARDĪ, 1976, p. 273). Suhrawardī, porém, retira sua inspiração do fim dessa narrativa aviceniana, quando o sábio Hayy ibn Yaqzān convida o recitante para segui-lo. Mas apenas isto. É incorreto, pois, afirmar que Suhrawardī tenha sido seguidor de uma "filosofia oriental e/ou iluminativa" de conteúdo místico elaborada por Avicena; ao contrário, ele explicitamente repudia qualquer filiação de sua doutrina a Avicena: "Embora ele (Avicena) atribua estes Cadernos ao Oriente (= Khurāsān), eles contêm os mesmos preceitos dos peripatéticos e da filosofia comum" (SUHRAWARDĪ apud GUTAS, 1988, p. 118, § 13).

Até mesmo Henry Corbin, defensor de uma filosofia "oriental-iluminativa" em alguns textos de Avicena, observa, em sua História da Filosofia Islâmica, que

Suhrawardī explica por que Avicena não poderia realizar o projeto de uma "filosofia oriental", uma vez que ignorava o princípio, a própria "fonte oriental", aquela que autentifica a qualificação de oriental. Avicena não 
conhecia esta fonte proveniente dos antigos sábios da Pérsia, isto é, a teosofia, a sabedoria por excelência (CORBIN, 1986, p. 287-288).

A maioria dos arabistas que se dedicaram à questão da Filosofia Oriental escreveu substanciais livros e artigos que discutem a problemática dos textos considerados por alguns místicos e/ou esotéricos no interior de um debate que vem acontecendo desde os séculos passados e que se reforçou com a publicação, em 1925, de um artigo de Carlo Alfonso Nallino, levantando a questão do título e do conteúdo desta obra de Avicena.

Cabe lembrar que a contenda entre os especialistas que se debruçaram sobre a Filosofia Oriental de Avicena permanece ainda hoje sem uma solução definitiva. As teses desses pesquisadores continuam, porém, sempre válidas, apesar das interpretações discrepantes, mas sempre filosóficas, dos textos de Avicena que geraram o debate. ${ }^{3}$

\section{A controvérsia acerca da filosofia oriental de Avicena}

Na continuação da Autobiografia de Avicena, na parte sobre a bibliografia, seu discípulo Jūzjānī informa que há apenas "alguns textos sobre a filosofia oriental (al-hikmat al-mashrikīya) que totalizam um volume" (GOHLMAN, 1974 apud GUTAS, 1988, p. 117-122). Como a posteridade recebeu a obra incompleta, permanece sem saber se Avicena chegou a completá-la ou se apenas escreveu o que temos hoje, ou seja, o Prólogo, a parte dedicada à Lógica e, de acordo com pesquisas recentes, algumas partes relativas à Física (GUTAS, 2000). Esta circunstância gerou numerosos debates tanto sobre o título da obra como sobre o seu conteúdo. Mas o conceito de "filosofia oriental" atribuído a alguns textos de Avicena é uma questão sem saída, como bem demonstrou Dimitri Gutas (GUTAS, 1988, p. 115-130). Em um artigo publicado em 2000, Gutas reitera que as propostas de uma "filosofia oriental e/ou iluminativa" atribuídas ao controvertido texto de Avicena nada têm a ver com o Avicena histórico e sua Filosofia Oriental (GUTAS, 2000, p. 166).

3 Contra o que a tradutora afirma: "As errôneas abordagens iniciais que insistiam num caráter místico como fundamento de seu pensamento foram paulatinamente contestadas à medida que suas obras [i. e., de Avicena] de filosofia iam sendo traduzidas" (DAMIEN, 2009, p. 109).

Rev. Filos., Aurora, Curitiba, v. 22, n. 30, p. 217-245, jan./jun. 2010 
A questão oscilava entre a existência e a ausência de um presumível misticismo e/ou esoterismo em alguns textos de Avicena. Inicialmente, o debate partiu dos possíveis significados das palavras-chave responsáveis pela polêmica, que, segundo o diacrítico, poderiam ser lidas como mashriqīya ou mushriquya. O vocábulo árabe mashriquya designa "oriental", mas, quando se muda o diacrítico inicial, obtém-se mushriqìya, que significa "iluminativa". Para chegar ao acordo terminológico definitivo acerca do título da controvertida obra, foi preciso esperar 1925, quando, enfim, Carlo Alfonso Nallino determinou o significado e a vocalização exatos para o termo que despertou tantas querelas.

Em seu artigo "Filosofia 'orientale' od 'illuminativa' d'Avicenna?", Nallino contesta o significado de "iluminativa" dado ao termo a partir de considerações relativas à própria língua árabe: o vocábulo mushriqūya poderia aplicar-se somente a pessoas, e não a uma coisa, ideia, livro, etc. "O nome filosofia mushriqiya [i. e., relativo à obra incompleta de Avicena] seria linguisticamente inverossímil" (NALLINO, 1925, p. 451). A prova disso está na obra de Suhrawardī, em que não há menção a mushriq ou mushriqī para designar qualquer coisa relativa à filosofia de $i s h r a \bar{q}$, mas surge apenas, e frequentemente, o termo ishraqī. Depois de apresentar suas considerações linguísticas, Nallino conclui que o título da obra de Avicena deve seguir a "velha e natural leitura, mashriquya (oriental)" (NALLINO, 1925, p. 451-452).

Neste mesmo artigo, Nallino percorre as propostas dadas pelos orientalistas para o significado possível do discutido termo árabe, que também surge no Prólogo da obra Hayy ibn Yaqzān, de Ibn Tufayl. A partir de Edward Pocock, o filho (1648-1727), que aceitou o significado de "oriental", os tradutores dessa obra de Ibn Tufayl passaram unanimemente a aceitar $\mathrm{o}$ adjetivo mashriquya (oriental), até que A. Tholuck, no século XIX, identificou a "filosofia oriental" de Avicena com a filosofia de ishrāq, pois este vocábulo árabe "corresponderia ao photismós dos neoplatônicos" (NALLINO, 1925, p. 439). Esta identificação, afirma Nallino, passou rapidamente a ser um lugar-comum entre os estudiosos do século XIX, como S. Munk, o qual chegou a afirmar, em seu livro Mélanges de Philosophie Juive et Arabe, publicado em 1859, que: "entre os célebres filósofos árabes, Ibn Bājjah (Avempace) e Ibn Tufayl parecem ter professado a filosofia dita ishrāq. Esta filosofia contemplativa, conforme Ibn Sīnā (Avicena), citada por Ibn Tufayl, dá o sentido oculto das palavras de Aristóteles" (MUNK, 1988 apud NALLINO, 1925, p. 440).

Ainda no mesmo século XIX, outro orientalista, De Slane, aceitou a versão do termo árabe para "iluminativa" (mushriqīya) e foi seguido por 
Carra de Vaux, o qual permitiu-se, em sua monografia sobre o filósofo persa, publicada em 1900, definir Avicena como "um adepto da filosofia iluminativa". Para confirmar esta tese, Carra de Vaux apoia-se na menção do discípulo Jūzjānī à "filosofia oriental", na lista que este dá das obras de Avicena (GOHLMAN, 1974, p. 46-47). Esta obra que, em geral, aparece com o título Filosofia Oriental (Al-Hikmat al-Mashrikiya), deveria, segundo o autor francês, receber o título de Filosofia Iluminativa (Al-Hikmat al-Mushrikīya) (CARRA DE VAUX, 1900, p. 151-153). O coroamento dessa leitura deu-se com Léon Gauthier, quando, no início do século XX, publicou uma tradução e um estudo sobre o Hayy ibn Yaqzān, de Ibn Tufayl (IBN TUFAYL, 1983, p. 1; GAUTHIER, 1983, p. 59-61).

Seguiram essa leitura M. Horten, M. Asín Palacios, Cl. Huart e T. J. De Boer. Esses estudiosos confirmaram o círculo vicioso de uma pressuposta identidade entre a "filosofia oriental" de Avicena com a posterior filosofia de ishrāq (iluminação) de Suhrawardī. Leram o termo como sendo mushriqūya (iluminativa) e, com isso, arbitrariamente transmitiram a ideia de que a "filosofia oriental" de Avicena contivesse doutrinas místicas e secretas. De fato, Asín Palacios, em seu estudo sobre a escola de Ibn Massara, chega a afirmar que Avicena ensinou uma filosofia mushriqūya (iluminativa), e não mashriqūya (oriental) (ASÍN PALACIOS, 1946, p. 160, n. 1), e, após a tradução alemã da seção dedicada à Metafísica no Livro da Cura (Kitāb al-Shifá)'), os especialistas Cl. Huart e T. J. de Boer, autores de dois verbetes na $1^{\text {a }}$ edição da Enciclopédia do Islã - Hikma e Ishrāqūyūn - conceberam a caracterização de uma "mística de cunho neoplatônico" no pensamento de Avicena e de uma "filosofia sincrética do helenismo que, chegada ao Oriente por meio de fontes neoplatônicas, herméticas e outras análogas, amalgamou-se às especulações da antiga Pérsia e a outras tantas" (apud GOICHON, 1955, p. 18).

A partir de 1930, nas comemorações dos 900 anos da morte de Avicena (maio-junho de 1037 - mês de Ramadã ou Shā 'ban, 428 da Hégira no calendário islâmico), foi reforçada a querela sobre a "filosofia oriental", que até hoje mantém divididas as opiniões dos especialistas. Muito se discutiu nesses debates que geraram e continuam a gerar polêmicas de importância, pois definem - ou procuram definir - os fundamentos epistemológicos do conjunto da obra de Avicena. Emergiram dessa polêmica duas correntes de interpretação com distintas acepções de conteúdo e cuja origem está assentada nas seguintes obras de Avicena: algumas epístolas, entre as quais os relatos de Hayy ibn Yaqzān e de O Pássaro, as três últimas seções do Livro das Diretrizes e Admoestações (Kitāb al-Ishārāt wa-l-Tanbīhāt) e um fragmento

Rev. Filos., Aurora, Curitiba, v. 22, n. 30, p. 217-245, jan./jun. 2010 
da obra perdida, a Filosofia Oriental (Al-Hikma al-Mashriqiya), cuja publicação em 1910, no Cairo, reforçou o problema, pois o editor egípcio publicou o fragmento sob o título de Lógica dos Orientais (Al-Mantiq al-Mashriqūyūn), uma vez que o manuscrito incompleto continha, além do Prólogo, uma pequena parte da Lógica. Mas, como bem observou Nallino, esse título é fictício (NALLINO, 1925: 455) e não encontra respaldo no próprio texto, pois não há no manuscrito sequer uma menção à expressão "lógica dos orientais" (GUTAS, 1988, p. 122, n. 22).

Já S. Pines, no mencionado artigo, alertou que as conclusões de Nallino em favor do termo mashriqūya (oriental), em detrimento de mushriqūya (iluminativa), "são considerações gramaticais que ele faz valer, justas em si mesmas e probatórias enquanto argumentos ad hominem, mas não levam em conta o fato de que a filosofia 'iluminativa' (ishrāqìya) suhrawardiana se vale de uma antiga tradição oriental (mashriqūya)" (PINES, 1953, p. 23).

Cabe lembrar que, para Pines, a "filosofia oriental" serviu a Avicena de "pretexto para explicar - sob o abrigo da adesão a uma tradição antiga suas reflexões pessoais com toda liberdade" (PINES, 1953, p. 32).

A filosofia de Avicena está mais próxima do modelo grego. De um lado, a morfologia, e de outro, as explicações do próprio Avicena no Prólogo da Filosofia Oriental não permitem supor que o filósofo almejasse outro objetivo senão o filosófico nesta sua obra de título controverso. No Prólogo, Avicena informa que escreverá um tratado que abarque todas as partes da filosofia, tal como o fez em sua obra Al-Shifä'; mas, visto que esta última se atém ao modelo peripatético, a Filosofia Oriental pretende se libertar do vínculo com o peripatetismo e apresentar o método dos orientais. A oposição dos orientais aos gregos não tem, portanto, uma coloração mística, mas exibe o modo de apresentar questões físicas e metafísicas, em que algumas posições aristotélicas são substituídas por outras derivadas do kalām e da teologia especulativa islâmica (NALLINO, 1925, p. 460). Nallino adverte que é provável que a diferença entre a Filosofia Oriental e outros tratados de Avicena esteja no método expositivo, e não no conteúdo filosófico. E conclui: "A Filosofia Oriental de Avicena é um tratado completo de filosofia em três seções (Lógica, Física e Metafísica), e não, como até agora se pensou, um escrito de mística esotérica" (NALLINO, 1925, p. 463). Recentemente, Dimitri Gutas apresentou o provável conteúdo da Filosofia Oriental com base no que restou do Prólogo de Avicena. A obra teria como objetivo seguir uma classificação das ciências a partir do desenvolvimento do pensamento de Avicena, e teria, pois, uma disposição diversa da do modelo aristotélico (GUTAS, 2000, p. 167-169).

Rev. Filos., Aurora, Curitiba, v. 22, n. 30, p. 217-245, jan./jun. 2010 
Por fim, o título do polêmico fragmento passou a ser aceito como Filosofia Oriental (Al-Hikma al-Mashriqīya ou Al-Falsafa al-Mashriqīya). Gutas, porém, questionou-o ao afirmar que, de acordo com as poucas fontes remanescentes, nem hikma (sabedoria) nem falsafa (filosofia) seriam termos apropriados para o seu título. A indicação de Avicena no Prólogo de Al-Shifă' sobre "o meu livro acerca da filosofia oriental" não autoriza o título de Filosofia Oriental para a obra perdida. Para Gutas, na falta de informações do próprio Avicena, o título mais correto para esta obra parcialmente perdida seria apenas Os Orientais (GUTAS, 1988, p. 122). ${ }^{4}$

$\mathrm{O}$ artigo de Nallino, porém, serviu de estímulo para a longa controvérsia. No prolongamento dessa discussão, pretendeu-se demonstrar que Avicena teria desenvolvido um misticismo neoplatônico que foi corroborado por sua obra perdida, e as importantes alterações de suas posições filosóficas teriam sido anunciadas no Prólogo que restou da sua Filosofia Oriental.

\section{O "misticismo" de Avicena}

A ideia de um "misticismo" contido em algumas obras de Avicena nasceu no século XIX com as publicações de Auguste F. Mehren, que, entre 1889 e 1899, editou um conjunto de textos avicenianos sob o título de Tratados Místicos de Avicena. Agrupados em quatro fascículos, os tratados foram publicados na revista Muséon. A publicação apresenta os textos no original árabe, acompanhados de traduções parciais, paráfrases, notas e análises críticas, e distribui-se da seguinte forma:

$1^{\mathrm{o}}$ fascículo:

A Alegoria Mística Hayy ibn Yaqzān (O Vivente, filho do Vigiante);

$2^{\circ}$ fascículo:

a) As três últimas seções do Kitāb al-Ishārāt wa-l-Tanbihāt (Livro das Diretrizes e Admoestações);

b) Sobre a Doutrina Süfi;

c) Tratado místico Al-Thayr (O Pássaro);

4 Em um posterior artigo, Gutas se refere à obra de Avicena com o título de Al-Hikma al-Mashriqīya apenas para simplificar as referências aos manuscritos estudados (GUTAS, 2000, p. 166-167). 
$3^{\circ}$ fascículo:

a) Risāla fi-l-Ishq (Epístola sobre o Amor);

b) Tratado sobre a natureza da oração;

c) Missiva sobre a influência produzida pela frequentação dos lugares santos e as orações que ai se fazem;

d) Tratado sobre a libertação do medo da morte;

$4^{\circ}$ fasículo:

Risāla fì-l-Qadar (Epístola sobre o Destino).

Em 1904, Mehren publicou, em Saragoça, uma glosa concernente a dois tratados avicenianos, Refutação dos Astrólogos e Epístola sobre o Destino, sem a edição dos textos originais em árabe. De um último texto de Avicena pertencente a este conjunto "místico", a Epístola de Salāmān e Absāl, o original desapareceu, porém foi parcialmente conservado graças ao resumo que Nasīr al-Dīn Tūsī inseriu em seu comentário ao Livro das Diretrizes e Admoestações, de Avicena.

No início do Prefácio ao primeiro fascículo da publicação na revista Muséon, Mehren adverte que a Alegoria Mística de Hay ben Yaqzān (grafado dessa forma na publicação) tem uma "certa importância para fixar as opiniões particulares do grande mestre da filosofia oriental" (MEHREN, 1979, p. 7). Faz menção ao fato de esse texto ter sido composto durante o cativeiro de Avicena na fortaleza de Ferdedjān, próxima a Hamadhān, no atual Irã. Mehren ainda afirma que, nesse opúsculo, Avicena expõe claramente "o sentido que se une à personificação dessa noção mística" de Hayy ibn Yaqzān, cuja tradução literal é Vivente, filho do Desperto/ Vigiante. Esse nome remete àquele que conduz a alma em sua jornada ascencional, o Sábio, filho daquele que, sempre alerta, vigia e cuida das almas de todos os seres humanos. Mas o próprio Mehren reconhece tratarse de uma "alegoria mística", como atesta o título que conferiu a este escrito de Avicena. E até mesmo Nallino, em seu artigo sobre a Filosofia Oriental de Avicena, afirma:

De fato, Avicena tem dois opúsculos de argumento místico que contêm os nomes de Hayy ibn Yaqzān, Absāl e Salāmān [...] Hayy ibn Yaqzān, símbolo do intelecto agente, é um ancião que faz conhecer o caminho ascéticomístico necessário para quem quer chegar, nos limites do possível, à união com Deus (NALLINO, 1925, p. 465). 
No catálogo do British Museum, informa Mehren, há uma justa observação que se refere ao texto como uma "alegoria sobre o intelecto agente". Para sua edição, Mehren serviu-se dos manuscritos do British Museum, os da Biblioteca Bodleyana de Oxford e os da Biblioteca de Leiden. Mehren ainda cita o romance filosófico de Ibn Tufayl (m. 1185), cujo título Hayy ibn Yaqzān foi tomado da obra homônima de Avicena, com conteúdo, porém, bem diferente. Para a edição árabe dos textos "místicos" de Avicena, Mehren usou o título Ibn Sīnā fi asrār al-hikma al-mashriqūya (Sobre os segredos da filosofia oriental de Avicena), o mesmo que aparece no subtítulo de Hayy ibn Yaqzān, de Ibn Tufayl.

Até o fim do século XIX, o Hayy ibn Yaqzān, de Ibn Tufayl, era bem conhecido e pouco se sabia acerca do texto homônimo de Avicena. Em razão do mesmo nome conferido ao personagem principal nas duas obras, alguns pesquisadores pensaram que Ibn Tufayl traduzira o opúsculo de Avicena; outros, porém, viram nele uma similaridade de conteúdos.

Nallino afirma que "não há dúvida de que Ibn Tufayl aludia a essas duas alegorias filosófico-místicas de Avicena" (isto é, às narrativas de Hayy ibn Yaqzān e de Salāmān e Absāl) quando, no Prólogo de sua novela filosófica, recorda "os mistérios da filosofia oriental, os quais Avicena menciona" (IBN TUFAYL, 1995, p. 31). Nallino, porém, observa que,

para os que conhecem os escritos místicos e não místicos de Avicena, é supérfluo observar que as palavras de Ibn Tufayl [...] devem ser compreendidas dentro de limites muito estreitos [...]: a comunhão de nomes dos personagens e o conceito da união místico-filosófica (NALLINO, 1925, p. 465).

Segundo Dimitri Gutas, defensor da unidade filosófica do sistema de Avicena, cujas raízes podem ser encontradas apenas na tradição aristotélica, Mehren se apropriou arbitrariamente do subtítulo dessa obra de Ibn Tufayl para a edição que preparou dos textos de Avicena que chamou de "místicos". Com o teor de sua Introdução e com o subtítulo Fī asrār al-hikma al-mashriqīya (Sobre os segredos da filosofia oriental), Ibn Tufayl, desse modo, involuntariamente contribuiu não só para que se atribuísse a Avicena uma "filosofia oriental" de viés místico, mas também para que se criasse a noção infundada de que essas duas obras homônimas lidam com a "filosofia oriental" (GUTAS, 1989 , p. 82). Para Gutas, essa identificação infundada causou um enorme dano que permaneceu ativo durante muito tempo, sendo ainda hoje manifesto (GUTAS, 2000, p. 164). 
Quanto à figura alegórica Hayy ibn Yaqzān, parece evidente, segundo Mehren, ter sido o próprio Avicena o primeiro a introduzi-la e a ter-lhe conferido a explicação do sentido "místico" que a ela se une. Na Epístola sobre o Destino (Risāla al-Qadar), Avicena faz uso do mesmo nome alegórico para introduzir o personagem que elucida as questões atinentes à responsabilidade que cabe a cada um no que se refere ao próprio destino. Mas, segundo Goichon, o nome Hayy ibn Yaqzān, dado ao intelecto agente, é de fácil compreensão à luz da teoria do conhecimento de Avicena: "Hayy (Vivente), uma vez que Avicena põe a perfeição da vida na inteligência e na ação; Ibn Yaqzān (filho do Desperto, do Vigiante) porque ele emana da penúltima inteligência pura que desconhece o sono e a desatenção" (GOICHON, 1971, p. 331).

$\mathrm{Na}$ teoria da emanação, que serve de referência teórica tanto a Al-Fārābī quanto a Avicena, a figura do sábio Hayy ibn Yaqzān, ao representar o intelecto agente, está além do mundo dos sensíveis e, por meio do conhecimento, guia a alma em direção ao Primeiro Princípio, o Ser que emana sua luz sobre todos os seres. Não há dúvida de que Ibn Tufayl tomou o título emprestado do opúsculo de Avicena, mas com o propósito de introduzir teses inteiramente distintas. ${ }^{5}$

Na década de 1950, as comemorações do milenário de Avicena reforçaram o debate sobre o misticismo e/ou esoterismo de Avicena, como atestam os artigos publicados na Revue du Caire em seu número especial de 1951, dedicado ao filósofo-médico persa. Georges C. Anawati, Louis Gardet e Louis Massignon estão presentes com artigos em que já os títulos refletem as tendências de seus autores a considerar místicos e/ou esotéricos os escritos de Avicena que geraram a polêmica.

Ao tratar da mística aviceniana, Louis Gardet considerou-a "intelectualista", uma vez que não se apresenta como uma "experiência" mística:

a mística aviceniana sempre dá a impressão de ser mais pensada que vivida: o desenvolvimento de uma linha conceitual que acredita tocar uma certa união mística e aspira, de certo modo, [a algo] como "do inferior ao superior", embora permaneça presa em seu próprio modo de conhecer (GARDET, 1939, p. 731).

Muito próximo a Platão, o sistema de Avicena, para Gardet, apresenta um duplo movimento: a descida ontológica desde os seres mais nobres até os

5 Sobre o Hayy ibn Yaqzān, de Ibn Tufayl, ver MONTADA, 2007, p. 145-177. 
seres inferiores e, depois, o retorno dialético dos intelectos inferiores até as inteligências mais puras. É o movimento do éros platônico que se reproduz no esquema filosófico aviceniano (GARDET, 1939, p. 725-726).

Em 1951, Gardet publicou La pensée religieuse d'Avicenne, um estudo em que observa como "as duas correntes, a aristotélica e a platônica, estão intimamente amalgamadas tanto na antropologia quanto na noética avicenianas" (GARDET, 1951a, p. 163). Neste estudo, Gardet apresenta a mística de Avicena no interior dos grandes esquemas metafísicos, noéticos e cosmológicos de seu sistema, sem os quais ela não pode ser compreendida (GARDET, 1951a, p. 195). Herdeiro de Platão, de Aristóteles, de Plotino e de Al-Fārābī, mas sobretudo de Platão e de Plotino, Avicena elaborou uma mística em que conceitualização e contemplação filosóficas têm primazia, já que "esta mística está estreitamente imbricada com suas intuições filosóficas fundamentais" (GARDET, 1951a, p. 195).

Na década de 1970, Abdurarahmān Badawī segue a ideia da "mística intelectualista" em certas obras de Avicena, já aventada por Louis Gardet. Badawī escreve:

[...] poder-se-ia chamar de mística intelectualista de Avicena. Mística ela o é por este arrebatamento em direção ao Ser Primeiro, essa ascensão por etapas que terá como resultado a união total da alma humana com a Fonte Primeira. Intelectualista, porque ela se distingue nitidamente da mística de um Hallāj, de um Ibn Arabī, por seu estrito apego à razão (BADAWĪ, 1972, v. II, p. 662).

A vida de Avicena, descrita por seu discípulo Jūzjānī na continuação da Autobiografia, está longe de ser a de um místico. Avicena deixou-se levar pelos prazeres da carne, em noitadas regadas a vinho e em encontros sexuais, o que afetou muito a sua saúde (GOHLMAN, 1974, p. 55/81-82). Mas isso não o impediu de elaborar uma "mística intelectualista", o que, porém, não é suficiente para indicar que Avicena tenha tido uma evolução mística de qualquer tendência (BADAWĪ, 1972, v. II, p. 665).

Badawī conclui suas páginas sobre a "mística intelectualista" de Avicena afirmando que ele não foi um racionalista puro. De fato, há em sua obra passagens em que Avicena aborda o irracional, como nas últimas seções do Livro das Diretrizes e Admoestações. Nelas, Avicena se deixa levar por noções "teosóficas e irracionais", nas palavras de Badawī, "como a previsão por meio de sonhos, a possibilidade da alma de elevar-se até a profecia, o conhecimento do invisível, as ações milagrosas" (BADAWİ, 1972, v. II, p. 665); 
também em sua opera magna de filosofia racional, Al-Shifä', precisamente em Metafísica X, Avicena recorre aos sonhos, às inspirações, às orações, às punições na vida futura, à adoração e sua utilidade neste mundo e no post-mortem. Por fim, Badawī questiona se de fato há uma duplicidade no sistema de Avicena, ou se há uma coexistência de duas tendências diametralmente opostas, mas conclui que a questão é de difícil resolução (BADAWĪ, 1972, v. II, p. 665).

\section{O "esoterismo" de Avicena}

Em seu estudo sobre a escola de Ibn Masarra, escrito em 1914, Asín Palacios (1946, p. 14, n. 3) afirma que "os mais renomados filósofos do Islã, como Al-Fārābī e Avicena, em algumas de suas obras inspiraram-se na mesma tendência mística e esotérica", isto é, a tendência sincrética e esotérica derivada da filosofia alexandrina e das doutrinas dos bātinīs e de alguns mu'tazilitas. O termo "esotérico" deriva do grego eso e refere-se aos textos lidos apenas para um seleto grupo em contraposição aos textos exotéricos, de exo, os que eram lidos para uma audiência maior. Esta é uma tradição que remonta a Platão e a Aristóteles. Asín Palacios menciona as ideias que ofendiam a fé ortodoxa e, por isso, seus autores procuravam divulgá-las "sob um véu de mistério". Desse modo, o caráter esotérico da falsafa, em seus primórdios, continuava a prática que revestia a filosofia alexandrina "nas tendências sincréticas e esotéricas que renasciam sob o disfarce islâmico" (ASÍN PALACIOS, 1946, p. 11).

Com relação ao sentido "esotérico" atribuído por alguns autores a algumas obras de Avicena, o próprio filósofo refere-se a ele em sua Epístola do Retorno (Risālat al-Adhawīya fi-l-Ma 'ād). Esta Epístola tem grande importância no conjunto da obra de Avicena, pois exprime sua própria opinião a um seleto grupo de amigos sobre o que ele entende com esse termo ( $m a$ ' $\bar{a} d$ ). Na Epístola, Avicena aborda o tema do destino do homem e da sobrevivência da alma à morte do corpo. Mais tarde, o tema deu origem às acusações de heresia, lançadas por Al-Ghazālī (1058-1111) aos filósofos helenizantes (falāsifa), especialmente a Al-Fārābī e a Avicena, em seu Tahāfut al-Falāsifa (Incoerência dos Filósofos). ${ }^{6}$

6 As três questões que Al-Ghazālī aponta como heresia dos filósofos são: 1) a pré-eternidade do mundo e a afirmação de que todas as substâncias são pré-eternas; 2) o conhecimento de Deus não abrange os particulares temporais entre os indivíduos existentes; 3 ) a recusa da ressurreição dos corpos e da sua presença no Dia do Julgamento (AL-GHAZĀLĪ, 2000, p. 226).

Rev. Filos., Aurora, Curitiba, v. 22, n. 30, p. 217-245, jan./jun. 2010 
O caráter esotérico da Epístola do Retorno decorre das opiniões adotadas por Avicena em relação à própria Lei divina, cuja revelação justifica o emprego de uma linguagem com expressões figuradas: "[...] se nos dirigíssemos ao povo com o argumento verdadeiro e se lhe falássemos da verdadeira felicidade e da verdadeira miséria, ele não saberia como representá-las e, desde a primeira impressão, considerá-las-ia como coisas impossíveis [...]." (AVICENA [IBN SĪNĀ], 1969, p. 38).

$\mathrm{Ou}$ :

[...] a justa afirmação, à qual é necessário voltar quando se quer fazer a exata profissão na unicidade divina [...], é proibido levá-la ao povo. Se chegasse nessa forma aos árabes de raça pura, aos hebreus, aos ignorantes, certamente estes se precipitariam em opor-se, e estariam todos de acordo no afirmar que a fé, à qual são chamados, é de todo vã (AVICENA [IBN SĪNĀ], 1969: 42-44).

Ou:

Tudo isto é um discurso para fazer compreender àquele que pede para participar da elite, e não à gente comum, a quem o sentido literal da Lei revelada não traz nenhuma prova em semelhantes argumentos [...]; o quarto enunciado, o sábio o conhece sem examiná-lo e, ao ignorante, é preferível não desvelá-lo [...] (AVICENA [IBN SĪNĀ], 1969, p. 62).

Ao refutar as falsas opiniões a respeito do retorno da alma à sua origem ( $\left.m a^{\prime} \bar{a} d\right)$, Avicena rebate, nesta última citação, o argumento daqueles que afirmam que "as consequências seriam detestáveis" se a Lei revelada fosse ensinada e compreendida em sentido literal a propósito das alegrias e das penas infringidas ao corpo sensível após a ressurreição dos mortos. O filósofo enfatiza que ao ignorante deve ser vedado o sentido profundo do $m a$ ' $\bar{a} d$, porque, em primeiro lugar, não seria capaz de compreendê-lo e, em segundo lugar, perderia a fé no Livro sagrado, o Corão. Fica evidente que o verdadeiro significado da Lei revelada é acessível apenas a uma elite. E Avicena continua: "De fato, se a recompensa e o castigo verdadeiros, que estão longe de seu entendimento, não fossem para eles representados [concretamente] e se não lhes aparecessem [em formas sensíveis], eles não seriam nem atraídos nem amedrontados [...]." (AVICENA [IBN SĪNĀ], 1969, p. 92). 
Essas afirmações, cujo sentido se repete em diversas outras obras, ${ }^{7}$ enfatizam a necessidade de um conhecimento "secreto", acessível apenas a uma elite de pensadores, e justificam um ensinamento "esotérico", cujas verdades são reservadas ao grupo seleto de "irmãos", possivelmente seus discípulos mais próximos. Avicena segue uma antiga tradição que pressupõe a distinção entre dois níveis de conhecimento e remonta à seguinte passagem de Platão: "Ao longo do caminho, abrem-se espaços sob as árvores onde poderemos repousar sob sua sombra; na nossa idade convém fazer paradas frequentes e, condescendendo ao prazer da conversação, levar com facilidade a termo todo o percurso" (Leis I, 625b).

Já Al-Fārābī assentira a essa tradição ao comentar essas palavras de Platão:

Platão menciona os ciprestes; recorda o caminho e suas estações que estavam sendo percorridos por seu interlocutor e inquiridor. Muitos acreditaram que isto contivesse noções mais penetrantes: que por "árvores" ele pressupunha "homens", e noções similares [igualmente] difíceis, forçadas e polêmicas, as quais tomariam muito tempo para serem explicadas. Mas o fato não é como pensam. Antes, ele [Platão] pretendia desse modo prolongar o seu discurso e estabelecer um elo entre o significado literal da discussão e algo que lhe correspondesse, embora estivesse se referindo a outros assuntos para ocultar sua intenção, sendo este o seu [real] propósito (AL-FĀRĀBĪ, 1963, p. 85-86).

Herdeiro dessa tradição, Avicena crê que a verdade da Lei revelada se expressa por meio de imagens sensíveis, físicas, apenas para os homens comuns, pois, nos significados ocultos das figuras alegóricas e metafóricas, o sábio e o filósofo saberão colher as verdades eternas. ${ }^{8}$

7 Livro das Diretrizes e Admoestações; Epistola do Pássaro; Epístola dos Estados da Alma; Mi 'rāj Nāma - O Livro da Ascensão do Profeta; Introdução à Filosofia Oriental.

8 Na terminologia técnica da exegese corânica, o sentido literal, aparente (zāhir), contrapõe-se ao sentido interno (bātin), do qual se apreende o significado sob a metáfora ou figuração mediante uma interpretação $\left(t a{ }^{\prime} w \bar{l} l\right)$. Os primeiros doutores do Islã professavam exclusivamente o sentido aparente ou literal do Corão. Mais tarde, o racionalismo dos mu 'tazilitas defendeu a interpretação do sentido metafórico dos versículos antropomórficos do Corão. A tradicional polêmica entre "metafóricos" e "literalistas" foi alimentada por discussões de teólogos que queriam demonstrar como o uso das imagens antropomórficas corânicas corresponde à tendência da própria língua árabe ao discurso figurado. Esses teólogos acreditavam encontrar na gramática e no estudo da linguagem o critério de interpretação da Lei revelada. 


\section{A Filosofia Oriental-Iluminativa de Henry Corbin}

Embora o próprio Avicena, o Sheikh al-Ra 'is - reconhecido entre os árabes pelo título de Príncipe de todas as ciências - tivesse mencionado uma filosofia oriental em sua obra, esta nada teria em comum com a "sabedoria iluminativa", filiada ao pensador persa Suhrawardī - posterior a Avicena em mais de um século -, cuja obra serviu de inspiração às interpretações de Henry Corbin. Para este, porém, as duas acepções, mashriqīya e mushriqūya, se complementam, pois "deveria haver um único termo para designar o conhecimento oriental, que é o Oriente do conhecimento" (CORBIN, 1986, p. 291).

Em relação às distintas interpretações acerca da Filosofia Oriental, o acordo terminológico sobre este título perdurou até os anos 1950, época em que Henry Corbin reviveu a antiga controvérsia, ao apresentar a defesa do conteúdo de uma gnose "iluminativa" em três conhecidos tratados de Avicena: Hayy ibn Yaqzān, O Pássaro e a Epistola de Salamān e Absāl.

Em 1952, em tiragem à parte publicada pela Unesco, surgiu, pela primeira vez, o estudo de Henry Corbin, Avicenne et le Récit Visionnaire, Le Récit de Hayy ibn Yaqzān (AVICENA, 1954). Contém o original árabe, a antiga versão e comentário anônimo em farsi, que Corbin atribui ao discípulo de Avicena, Jūzjān̄̄, com tradução francesa e uma introdução. Em 1954, foi publicada, em Teerã, na coleção dirigida por Corbin, Bibliothèque Iranienne, a tiragem da Unesco acompanhada das Notes et Gloses de la Traduction du Récit de Hayy ibn Yaqzān. Esse conjunto constitui o volume II dessa obra de Corbin. O volume I, Avicenne et le Récit Visionnaire, reimpresso em 1979, contém a tradução e o estudo que Corbin fez dos três citados escritos, os quais compõem um ciclo unitário que o autor nomeou de Ciclo das Narrativas Visionárias de Avicena, e devem ser compreendidos como uma trilogia. Para Corbin, o fato de serem narrativas não permite que sejam consideradas "alegorias" ou "histórias".

Esse ciclo tem, para Corbin, o significado de uma doutrina organizada cientificamente, que, entretanto, denuncia o roteiro de uma aventura mais pessoal. $\mathrm{O}$ ciclo situa o homem Avicena no cosmo que o próprio filósofo elaborou ao narrar uma aventura pessoalmente vivenciada. E, ao mesmo tempo, as narrativas parecem responder à pergunta "onde situar o avicenismo na totalidade dos sistemas filosóficos?", visto que a filosofia de Avicena seguiu diferentes rumos no Oriente e no Ocidente. Corbin afirma que a filosofia tradicional, alimentada por velhas fórmulas, pode, enfim, ser capaz de aceitar 
uma nova abordagem, desde que levada em conta a aventura espiritual enfrentada pelo próprio Avicena.

O estudo das narrativas místicas de Suhrawardī levantou, para Corbin, uma questão cuja resposta era capital: qual seria a parte de inspiração aviceniana que permanece na obra do Mestre de $I s h r a \bar{q}$ ? A pesquisa de Corbin levou-o a confrontar a teosofia de Suhrawardī - a doutrina do Oriente das Luzes - com a proposta aventada por Avicena de uma filosofia ou sabedoria oriental. Ao aproximar as obras dos dois autores persas, Corbin conclui, a despeito das divergências encontradas em seus grandes tratados teóricos, que há uma convergência para a compreensão de uma fenomenologia dos símbolos. Como já mencionado, Suhrawardī retira sua inspiração do fim da Narrativa de Hayy ibn Yaqzān. Para o erudito francês, esta narrativa aviceniana responde, com muita clareza, ao que significa para Avicena o conceito de Oriente, com certeza um Oriente que não pode ser buscado nos atlas geográficos.

Assim, em seus estudos que contemplam a "sabedoria oriental" embutida na trilogia aviceniana, Corbin tem como ponto de partida a obra do persa Suhrawardī. Aproxima a sabedoria iluminativa (ishrāqīya) e a sabedoria oriental (mashriqīya) e insiste na tese de que não há distinção alguma de conteúdo entre ambas, pois o Sol da aurora desponta no Oriente (Mashriq) e jorra sua luz sobre o mundo. Os raios de luz do Sol nascente atraem a alma. O Oriente é contemplado como fonte transcendente da luz, símbolo do conhecimento "oriental", porque toda luz vem sempre do Oriente. A "orientação" infundida à alma é a indicação do caminho rumo à luz (CORBIN, 1979, p. 47-48; 1990, p. 156).

Desse modo, na teosofia das luzes, os termos ishrāq e ishrāqī remetem-se simultaneamente seja à noção de "iluminação" seja à de "oriental". Ishrāq $\bar{l}$ qualifica quer o modo de conhecimento espiritual, quer o grupo de sábios cujo objetivo é atingir o conhecimento hierático. Corbin adverte que ambos estes termos não possuem qualquer conotação geográfica ou étnica (CORBIN, 1979, p. 51). Na teosofia das luzes, a "iluminação" tem significado diverso daquele comumente aceito na teologia cristã. A iluminação cristã é uma dádiva de Deus; a visão da luz dos "orientais" é um fenômeno que pertence ao místico, é algo que brota de seu interior. Não se trata, portanto, da graça divina entendida como um dom recebido do poder divino, já que significa a culminação dos esforços do teósofo hierático (na terminologia de Corbin), em sua peregrinação rumo ao conhecimento (= gnose). Do ponto de vista dessa teosofia, o termo ishrāq $\bar{\imath}$ remete-se tanto aos "orientais" do Ocidente quanto aos do Oriente geográficos, pois o sentido da palavra "Oriente" diz respeito à 
luz que no Oriente desponta. O termo Oriente, portanto, possui essa dupla significação, visto que, na correspondência com o esplendor da aurora, simboliza o instante epifânico do conhecimento de si. O sujeito do conhecimento chega ao Oriente no instante em que atinge o conhecimento. Apreender o conhecimento e alcançar o Oriente são sinônimos que designam o movimento com o qual o iniciado está comprometido e cujo objetivo último é receber a luz ou gnose (= conhecimento) (CORBIN, 1971, v. II, p. 47; 1979, p. 45)

No Irã, afirma Corbin, tem-se por hábito separar os filósofos peripatéticos ou discípulos de Aristóteles (mashsh'ūn) dos filósofos platônicos e neoplatônicos conhecidos (ishrāqūs), os teósofos de ishrāq ou Oriente das puras luzes. Conforme Corbin, não há um filósofo ishraqī que não seja um pouco aviceniano. A prevalência filosófica de Avicena e de Suhrawardī é atestada no pensamento iraniano até nosso dias (CORBIN, 1979, p. 14).

\section{A fenomenologia e a hermenêutica de Corbin}

Henry Corbin é um pensador preocupado em elaborar um método próprio para interpretar os textos que estuda. Para isso, ele se vale de uma fenomenologia independente de qualquer outra escola fenomenológica, pois parte do significado do grego sôzein tà phainómena, salvar os fenômenos, isto é, preservar o aparente. O fenômeno é o que aparece, é o que se mostra. Sob sua aparência, porém, revela-se algo que simultaneamente permanece velado. No fenômeno, portanto, há algo que se revela, que, porém, não pode se revelar senão se ocultando. No aparente ou exterior (zāhir) esconde-se o oculto (bātin), o qual se desvela por meio do fenômeno exterior. A fenomenologia de Corbin consiste em "salvar o aparente" ao desvelar o oculto que nele se esconde, isto é, ao mostrar e discorrer sobre o invisível que se apresenta sob o visível, ao discernir o significado oculto contido na letra (CORBIN, 1985, p. 22-23). Essa fenomenologia é, pois, uma hermenêutica, uma interpretação $(t a$ ' $w \bar{l} l)$, que procura extrair dos textos os seus sentidos ocultos; é uma hermenêutica dos sentidos espirituais escondidos no sensível (CORBIN, 1971, v. I, p. 141); é uma hermenêutica do esotérico, isto é, do oculto, a qual o faz remontar à sua origem, ao seu arquétipo (CORBIN, 1971, v. I, p. 19-28).

Corbin desenvolveu seu método de exegese a partir das teses de Swedenborg (1688-1772). A palavra sagrada se apresenta, no exterior, com um sentido literal e corresponde ao "envelope" que contém e sustenta o sentido interior ou espiritual. O sentido espiritual contém em si um outro sentido, mais

Rev. Filos., Aurora, Curitiba, v. 22, n. 30, p. 217-245, jan./jun. 2010 
profundo e interior, este último correspondente ao sentido celestial. Sentido espiritual e sentido celestial estão ambos contidos no sentido literal. Em tudo que é divino, há três níveis: o original, o intermediário e o último, o que faz com que o original exista nos três níveis. Cada coisa no mundo, se estiver completa, é constituída por essa tríade constitutiva da palavra sagrada. No sentido literal está oculto o sentido espiritual, que por sua vez contém um sentido mais "íntimo", o sentido celestial (CORBIN, 1971, v. I, p. 139).

Corbin não concebe a sua hermenêutica como interpretação do sentido aparente por meio de significados ocultos, como se estes se apresentassem sob as vestes de uma verdade "alegorizada". Para o pensador francês, a alegoria anula o vínculo simbólico que une o aparente ao oculto. Do verbo grego symbaleîn, que significa reunir, juntar, aproximar, derivou o termo símbolo, merecedor de uma ampla literatura dedicada a teorizar sobre suas tantas acepções na história do pensamento ocidental. Corbin parte do significado original de "reunião" para construir a teoria do vínculo entre o que é aparente, a letra, e o que é oculto, o sentido espiritual.

O sentido oculto (bātin) diz respeito a um plano superior em que o que se manifesta em cores mundanas, ou nos versos da letra, revive e vivifica. O aparente (zāhir) encontra sua verdadeira natureza, a de aparecer, mediante a exegese que transporta o aparente aos planos superiores do ser. Como o próprio Corbin afirma, o aparente simboliza com o oculto, o que significa que a exegese possui a finalidade de desvelar o vínculo que une ambos, o aparente e o oculto. A exegese faz a letra ascender do plano aparente de significações semânticas para o plano superior de significados ocultos. Esse primeiro movimento de ascensão, quando a letra se faz símbolo revestido de significado simbólico, é seguido de um segundo momento, a descida, quando a letra reveste o sentido aparente com toda a sua potência de símbolo.

Pertencentes a um plano superior, os significados simbólicos revivem e "aparecem" na sua real natureza no ato exegético. A exegese tem por finalidade desvelar o vínculo indissolúvel que une o aparente ao oculto, ou seja, decifrar o sentido velado contido na letra (CORBIN, 1971, p. 141-153, v. I). Subir e alcançar o significado oculto, em seguida descer até o seu significado aparente para imprimir-lhe toda a sua potência adquirida na ascensão exegética, são esses o movimento da exegese do texto.

Ao elaborar sua hermenêutica fenomenológica a partir dos textos iranianos, Corbin segue os passos do antigo conhecimento dos hermetistas e dos cristãos gnósticos considerados heréticos pela ortodoxia da Igreja nos primeiros séculos de nossa era, para os quais o verdadeiro conhecimento se 
traduz na "vivência" da alma em sua busca da verdade divina. A "situação hermenêutica" converte-se assim em "situação gnóstica". A hermenêutica fenomenológica corbiniana nos conduz, portanto, de uma manifestação menor, registrada na imperfeição sensível, para uma manifestação maior, a de uma humanidade divinizada.

\section{A narrativa de Hayy ibn Yaqzān: Corbin $\times$ Goichon}

A Narrativa de Hayy ibn Yaqzān obriga o estudioso a reinterrogar as relações entre aristotelismo, platonismo e neoplatonismo na chave de antigas tradições à margem da filosofia. No feitio de epístola (risāla) e em linguagem figurada, Avicena narra o percurso da alma rumo ao conhecimento. Seu tema, a viagem da alma, vislumbra não apenas considerações rigorosamente filosóficas, mas ainda a busca de sentidos ocultos presentes nessas tradições orientais. Dessa polaridade de conteúdo, originaram-se duas distintas interpretações do relato aviceniano: a primeira apoia-se na gnose iraniana e tem em Henry Corbin seu contumaz defensor. A segunda assenta-se na arquitetura do sistema de Avicena e faz da análise de Amélie-Marie Goichon um imperativo na filosofia da razão (AVICENA, 1959).

No quadro referencial de uma filosofia de contornos neoplatônicos, as formas substanciais são dadas aos seres terrestres pelo intelecto agente, última das inteligências puras e regente do mundo sublunar, tal como as outras inteligências regem cada uma delas sua própria esfera celeste. No mundo da matéria, as formas estão num incessante movimento de alteração e devir. Cabe à alma humana capturar as formas emanadas no mundo terrestre pela décima inteligência, o doador de formas (ár. wāhib al-suwar; lat. dator formarum). No sentido inverso do itinerário de recepção, a alma eleva-se ao conhecimento das formas puras no movimento ascendente, simbolicamente contemplado na Narrativa de Hayy ibn Yaqzān, cujo Oriente e Ocidente correspondem, respectivamente, ao mundo dos inteligíveis e ao mundo da matéria. A alma, porém, não é capaz de atingir a abstração por si própria: necessita do auxílio do intelecto agente - um anjo na cosmologia aviceniana. A viagem impõe o esforço para que a alma domine os instintos do corpo - concupiscência, irascibilidade e imaginação. Desvinculada da matéria e livre dos sentidos corporais, a alma, então "preparada", recebe do intelecto agente as formas inteligíveis. Não pode haver conhecimento e apreensão do inteligível, luz da alma, se esta não estiver liberta da percepção dos sentidos corporais. O Oriente, reino das 
formas, dos inteligíveis e das inteligências, só concede à alma o seu ingresso nele com a cooperação do intelecto agente. A alma está presa ao Ocidente material por sua fraqueza de espírito, e, para Avicena, a moderação é a regra necessária para empreender o caminho em direção à luz. O Ocidente, símbolo do mundo da matéria, região do poente solar, é o "clima" onde formas "iluminadas", emanadas do intelecto agente, "caem" prisioneiras - trágico destino traduzido nos versos melancólicos do Poema da Alma, atribuído a Avicena. Teoria metafísica e noética, a concepção da Origem e do Retorno de Avicena é tema recorrente em seu sistema filosófico, que visa à união da existência àquela da inteligência.

Para Corbin, porém, a Narrativa de Hayy ibn Yaqzān é uma iniciação ao Oriente, mundo das formas puras e arcangélicas de luz, oposto ao mundo da matéria. O próprio nome do anjo, Hayy ibn Yaqzān, sugere a epifania, pois significa "vivente, filho daquele que está sempre desperto, o velador das almas"; pois, ao velar as almas, o Ser Supremo agracia as que percorrem o caminho em direção à luz. E, para guiá-las em sua viagem de retorno à origem, o anjo realiza sua função de doador de formas, aquele que sobre os mortais derrama os inteligíveis, o conhecimento das luzes.

Na hermenêutica corbiniana, a função do intelecto agente, personificado pelo sábio Hayy ibn Yaqzān, não está apenas ancorada na teoria do conhecimento, ou seja, limitada a proporcionar o derramamento das formas inteligíveis no mundo sublunar; ao contrário, o intelecto agente se transmuta e adquire uma função, cunhada por Corbin como "pedagogia angélica": a epifania do anjo - personificado no Sábio, condutor da alma em sua jornada celestial - corresponde ao momento específico e ao grau determinado de individuação da alma, quando esta desperta e se conscientiza de seu estranhamento no mundo. Esse momento culmina na sua liberação do mundo terreno e se sintoniza com o instante em que se funde à sua origem, representada na figura do Sábio-anjo. Prisioneira no cosmo, ela é necessária ao guia para que este realize e cumpra sua tarefa divina.

O conceito Oriente-Ocidente parece ser o eixo em torno do qual divergem as duas correntes interpretativas. Corbin, ao contrário de Goichon, não se ocupou da totalidade da obra de Avicena. Deteve-se no estudo da gnose iraniana e, para isso, valeu-se dos textos "alegóricos" de Avicena, visto que o filósofo persa é filho do universo geográfico e temporal das investigações do erudito francês. É apenas nesse contexto que as análises de Corbin são pertinentes e válidas. Goichon investe contra a hermenêutica espiritualista de Corbin: sua tese está ancorada no pressuposto de que Avicena escrevia o que 
realmente queria dizer, e se "a linguagem de seu texto não corresponde a nenhuma gnose" é porque certamente outra era a sua intenção. Para Goichon, os textos responsáveis pela controvérsia não passam de "parábolas filosóficas".

Contudo, a propósito da Narrativa de Hayy ibn Yaqzān, a pergunta fundamental foi feita por Georges C. Anawati (1963, p. 172): "por que Avicena escolheu, ou melhor, por que foi espontaneamente levado a 'imaginar' esse tema e a construir esse 'romance espiritual' que Goichon repele com tanta energia?".

Dois métodos distintos, duas interpretações diferentes, não há como comparar o trabalho de Corbin com o de Goichon. Suas propostas e perspectivas seguem rumos separados, o que não significa que se deva preterir uma abordagem em favor da outra. Ambas contribuem igualmente para o estudo da obra de Avicena. Ao leitor atento, basta conhecê-las. Pois, como afirmou Paul Ricoeur, "feliz e raro seria o encontro, no seio de uma mesma filosofia, entre a abundância dos signos e dos enigmas retidos, e o rigor de um discurso sem complacência" (RICOEUR, 1978, p. 250).

\section{Referências}

FONTES PRIMÁRIAS

AL-FĀRĀBĪ. Plato's Laws. Traduction by Muhsin Mahdi. In: LERNER, R.; MAHDI, M. (Org.). Medieval political philosophy: a sourcebook. Ithaca: Cornell University Press, 1963. p. 83-94.

AL-GHAZĀLİ. The incoherence of the philosophers (Tahāfut al-Falāsifa). Traduction, Introduction and notes by Michael M. Marmura. Provo (Utah): Brigham Young University Press, 2000. Arabic-English edition.

AVERROES. Tahafut al-Tahafut (The incoherence of the incoherence). Translated from the Arabic with introduction and notes by Simon van den Bergh. London: Luzac, 1954.

AVICENA (IBN SĪNĀ). Kitāb al-Ishārāt wa l-Tanbīhāt: livre des directives et remarques. Traduction (français) en arabe, introduction et notes par A-M. Goichon. Beyrouth; Paris: J. Vrin, 1951.

Avicenne et le récit visionnaire: Hayy ibn Yaqzān. Texte arabe, version et commentaire en persan atribués à Jūzjānī. Traduction, notes et gloses. 2ème éd. Paris: Adrien Maisonneuve. 1954. Tome II. 
Risālat Ḥayy ibn Yaquān: le récit de Ḥayy ibn Yaquān, commenté par des textes d'Avicenne. Avant-propos, traduction, explications et notes par A-M. Goichon. Paris: Desclée de Brouwer, 1959.

. Epistola sulla vita futura. Padova: Ad. Antenore, 1969.

. Traités mystiques d'Aboû al-Hosain b. Abdallâh b. Sînâ ou Avicenne. Textes arabes, explications, traductions partielles en français, notes et analyses critiques par Auguste F. Mehren. Leiden 1889-1899. Holland: Holland University Press, 1979. 4 fasc. v. 1. Réimpression de l'édition originale.

- Avicena: tres escritos esotéricos. Traducción y notas de Miguel Cruz Hernández. Madrid: Tecnos, 1998.

IBN TUFAYL. Hayy ben Yaqdhân. Roman philosophique d'Ibn Thofaïl texte arabe avec les variantes des manuscrits et de plusieurs éditions et traduction française. 2ème éd. rev., augm. et complètement remaniée, par Léon Gauthier. Paris: J. Vrin. 1983. Reprise de l'édition de Beyrouth, 1936.

El filósofo autodidacto. Risāla Hayy ibn Yaqzān. Traducción del Ángel González Palencia. Edición de Emilio Tornero. Madrid: Editorial Trotta, 1995.

SUHRAWARDĪ (SOHRAVARDĪ). L'Archange empourpré. Quinze traités mystiques traduits du persan et de l'arabe annotés et présentés par Henry Corbin. Paris: Fayard, 1976. Coll. Documents spirituels, 14.

SUHRAWARDĪ, Y Ḥ. L'archange empourpré: quinze traités et récits mystiques / Shihâboddîn Yahyâ Sohravardî; traduits du persan et de l'arabe, présentés et annotés par Henry Corbin. Paris: Fayard, 1976.

\section{FONTES SECUNDÁRIAS}

ANAWATI, G. C. Un cas typique de l'ésoterisme avicennien: sa doctrine de la résurrection des corps. La Revue du Caire. Millénaire d'Avicenne (Abou Ali Ibn Sina), v. 14, n. 141, 1951. p. 68-94. Numéro special.

. Gnose et philosophie: a propos du Récit de Hayy ibn Yaqzān de A.-M. Goichon. Cahiers de Civilisation Médiévale, v. VI, n. 2, p. 159-173,1963.

BADAWĪ, A. Histoire de la philosophie en Islam. Paris: J. Vrin, 1972. v. 2.

CARRA DE VAUX. Avicenne. Paris: Felix Alcan, 1900. 
CORBIN, H. En Islam iranien. Aspects spirituels et philosophiques. 4 v.; v. I: Le Shî’isme duodécimain; v. II: Sohrawardî et les platoniciens de Perse. Paris: Gallimard, 1971.

. Avicenne et le récit visionnaire. (1962). Paris: L’île Verte; Berg International, 1979.

. Philosophie iranienne et philosophie comparée. Paris: Buchet/ Chastel, 1985.

. Histoire de la philosophie islamique (1964). Paris: Gallimard, 1986.

. L'Iran et la philosophie. Paris: Fayard, 1990.

DAMIEN, C. Introdução à tradução do artigo de Goichon, Marie-Amélie: "O Pretenso Esoterismo de Hayy ibnYaqzân”. Revista Tiraz, ano VI, n. 6, p. 109$110,2009$.

GARDET, L. Quelques aspects de la pensée avicennienne. Revue Thomiste, n. 3/4, p. 537-575/693-742, 1939.

. La pensée religieuse d'Avicenne (Ibn Sīnā). Paris: J. Vrin, 1951a.

. Avicenne et le problème de sa "Philosophie Orientale". La Revue du Caire. Millénaire d'Avicenne (Abou Ali Ibn Sina), 14èmme anné, n. 141, p. 13-22, 1951 b. Numéro special.

. L'expérience mystique selon Avicenne. La Revue du Caire. Millénaire d'Avicenne (Abou Ali Ibn Sina). 14èmme anné, n. 141, p. 56-67, 1951c. Numéro special.

GAUTHIER, L. Ibn Thofaill, sa vie, ses oeuvres. Paris: J. Vrin, 1983. Reprise de l'édition de 1909.

GOHLMAN, W. E. The Life of Ibn Sina. A critical edition and annotated translation. Albany: State University of New York Press, 1974.

GOICHON, A-M. Réponse aux "Récentes Études Avicenniennes" de M. Georges Vajda. Extrait du Journal Asiatique, n. 240, p. 497-511, 1952.

. (1955) Philosophie et histoire des sciences. Les Cahiers de Tunisie, n. 9, p. 17[1]-40[24], 1955.

. Le prétendu ésotérisme d'Avicenne dans le Récit de Hayy ibn Yaqzān. Giornale di Metafisica, n. 4, 1959. p. 538-546. 
Hayy ibn Yaqzān. In: GOICHON, A-M. The Encyclopaedia of Islam. v. III.

Leiden: E. J. Brill; London: Luzac \& Co., 1971. p. 330-334.

GÓMEZ NOGALES, S. El misticismo persa de Avicena y su influencia en el misticismo español. Milenario de Avicena. Cuadernos del Seminario de Estudios de Filosofía y Pensamiento Islámicos, n. 2, 1981. p. 65-88.

GUTAS, D. Avicenna and the aristotelian tradition. Leiden: E. J. Brill, 1988.

Avicenna. Verbete V. Mysticism. In: GUTAS, D. Encyclopaedia Iranica, v. III. Edited by Ehsan Yarshater. London. New York: Routledge \& Kegan Paul, 1989, p. 79-83.

. Ibn Tufayl on Ibn Sīnā’s Eastern philosophy. Oriens, v. 34, p. 222-241, 1994.

Avicenna's Eastern (“Oriental”) philosophy: nature, contents, transmission. Arabic Sciences and Philosophy, n. 10, 2000. p. 159-180.

KARAM, Y. La vie spirituelle d'après Avicenne. La Revue du Caire. Millénaire d'Avicenne (Abou Ali Ibn Sina), 14èmme anné, n. 141, p. 44-55, 1951. Numéro special.

MACUCH, R. Greek and oriental sources of Avicenna's and Sohrawardī's theosophies. Graeco-Arabica, n. 2, p. 9-22, 1983.

MASSIGNON, L. Avicenne e les influences orientales. La Revue du Caire. Millénaire d'Avicenne (Abou Ali Ibn Sina). 14èmme anné, n. 141, p. 10-12, 1951. Numéro special.

. La philosophie orientale d'Ibn Sīnā et son alphabet philosophique. Memorial Avicenne IV, Miscellanea, Cairo: Publications de l'Institut Français d'Archéologie Orientale du Caire, 1954.

MEHREN, A. F. Préface. In: AVICENA (IBN SĪNĀ) Traités Mystiques d'Aboû al-Hosain b. Abdallâh b. Sînâ ou Avicenne. Textes arabes, explications, traductions partielles en français, notes et analyses critiques par Auguste F. Mehren. Holland University Press, 1979. 4 fasc. en 1 vol. Réimpression de l'édition: Leiden 1889-1899.

MICHOT, J. La destinée de l'homme selon Avicenne. Louvain: Aedibus Peeters, 1986.

MUNK, S. Mélanges de Philosophie Juive et Arabe. Paris: J. Vrin, 1988. Édition fac-similé de la première édition en 1859. 
NALLINO, C. A. Filosofia "orientale" od "illuminativa" d'Avicenna? Rivista degli Studi Orientali, Roma (1923-1925), v. X, p. 433-467, 1925. Reimpresso in: Raccolta di scritti editi e inediti. Roma: Istituto per l'Oriente, 1948. v. VI, p. 218-256.

PALACIOS, M. A. Ibn Masarra y su escuela. Orígenes de la filosofia hispanomusulmana. In: Obras Escogidas. v. I. Madrid; Granada: CSIC; Instituto Miguel Asín; Escuelas de Estudios Árabes de Madrid y Granada, 1946. p. 1-216.

PEREIRA, R. H. de S. Avicena: a viagem da alma. São Paulo: Perspectiva, 2002; 2005.

PINES, S. La "Philosophie Orientale" d'Avicenne et sa polémique contre les bagdadiens. Archives d'Histoire Doctrinale et Littéraire du Moyen Âge, n. 19, p. 5-37, 1953. Vingt-septième année, 1952.

PUIG MONTADA, J. Ibn Tufayl e a aventura da humanidade. In: PEREIRA, R. H. de S. (Org.). Busca do conhecimento: ensaios de filosofia medieval no Islã. São Paulo: Perspectiva, 2007. p. 145-177.

RICOEUR, P. O conflito das interpretações: ensaios de hermenêutica. Rio de Janeiro: Imago, 1978.

Recebido: $02 / 02 / 2010$

Received: 02/02/2010

Aprovado: $12 / 05 / 2010$

Approved: 05/12/2010 